\title{
LA CONCEPCIÓN DE LA AUTORIDAD COMO SERVICIO PUESTA A PRUEBA
}

\author{
Ángeles Ródenas \\ Universidad de Alicante
}

RESUMEN. El objeto de este trabajo es cuestionar la tesis normativa contenida en la concepción de la autoridad como servicio de Raz, así como algunos de los presupuestos conceptuales sobre los que dicha concepción se asienta. Respecto de la tesis normativa, se muestra que la concepción de la autoridad como servicio no es una concepción completa, esbozando para ello las características genéricas de dos tipos de situaciones comprometedoras para dicha concepción. Estas dos situaciones comprometedoras no son sino ejemplificaciones de algunos argumentos clásicos empleados por la filosofía política para justificar la autoridad. La idea es que nuestra concepción actual de la autoridad es el resultado de una sucesión histórica de necesidades, experiencias y reflexiones capaces de proporcionar razones que, aunque en algunos contextos operen entimemáticamente, son plenamente operativas. Recalar en estas construcciones y no hacer borrón y cuenta nueva lleva a cuestionar algunos de los presupuestos conceptuales sobre los que se asienta la concepción de la autoridad como servicio y a extraer alguna lección útil de cara a la articulación de una concepción integradora de la autoridad.

Palabras clave: Raz, legitimidad de la autoridad, concepción de la autoridad como servicio.

ABSTRACT. The purpose of this work is to question two dimensions of Raz's service conception of authority: its normative thesis and some of the conceptual grounds underlying that conception. Concerning the normative thesis, an outline of two types of compromising situations for the service conception proves that this conception is not complete. These two compromising situations are only instantiations of some classic arguments used in political philosophy to justify authority. The idea is that our current conception of authority is the result of a historical succession of necessities, experiences and reflections that provide reasons which are fully operative although they operate entimematically in some contexts. To be aware of these constructions and not simply to ignore them leads to questioning some of the conceptual grounds upon which the service conception is based, and to obtaining some useful lessons in order to implement a comprehensive authority conception.

Keywords: Raz, legitimation of authority, service conception of authority. 


\section{INTRODUCCIÓN}

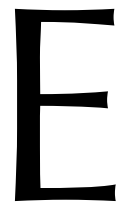

$\mathrm{n}$ un reciente trabajo que lleva por título «El problema de la autoridad: De nuevo sobre la concepción de la autoridad como servicio» ${ }^{1}$, Joseph RAZ responde a muchas de las objeciones que a lo largo de los últimos años se han dirigido contra la concepción de la autoridad como servicio, introduciendo algunos matices y terminando de perfilar los aspectos centrales de su concepción. Como quiera que también yo hace algún tiempo me ocupé del problema de la justificación de la autoridad política y, muy centralmente, de la concepción de RAZ², el reto para mí estaba servido: poner a prueba la solidez de esta nueva versión de la concepción, oponiéndole algunas objeciones también mucho más refinadas.

Voy a dar por sentado que el lector conoce ya cuáles son las líneas maestras de la concepción de la autoridad como servicio. De manera que aquí sólo voy a exponer brevemente aquellos presupuestos conceptuales que figuran en la nueva versión de la concepción de la autoridad de RAZ que me sean indispensables para que mi crítica resulte inteligible. Algunos de esos aspectos suponen novedades respecto de la versión original de la concepción, mientras que otros son simples refinamientos de tesis anteriores. Concretamente son cuatro los aspectos de esta nueva versión que voy a destacar, a saber:

\subsection{Primero: el carácter normativo del concepto de autoridad}

El carácter normativo del concepto de autoridad es una idea que está presente en RAZ ya desde las primeras versiones de la concepción de la autoridad como servicio ${ }^{3}$. La dependencia de la noción de autoridad de facto respecto de la de autoridad legítima es un presupuesto metodológico raziano fundamental. RAz ha insistido siempre en que una persona necesita más que poder (como influencia) para ser autoridad de facto. Para que alguien sea autoridad de facto no basta con que pueda imponer decisiones usando la fuerza bruta, sino que además es necesario que se produzca el reconocimiento por un número significativo de personas de que tal imposición está bien fundada. Es necesario, en suma, que la gente crea que se trata de una autoridad legítima (lo sea realmente o no). Si para predicar de alguien que es una autoridad de facto debemos de tener (al menos) algunas creencias en torno a qué le hace una autoridad legítima, cualquier intento por esclarecer qué es una autoridad de facto pasa primero por indagar qué es lo que consideramos como autoridades legítimas, y no a la inversa.

Una cuestión conexa a la anterior de la que se ocupa ahora nuestro autor, y que supone una novedad, es de las dificultades para elaborar un concepto explicativamente neutro de autoridad. RAZ entiende por concepto explicativamente neutro aquel que per-

\footnotetext{
${ }^{1} C f r$ «El problema de la autoridad: De nuevo sobre la concepción de la autoridad como servicio» (trad. de Paula GAIDO), en este número de Doxa, 29-2007. cionales.

${ }^{2}$ Cfr. RóDEnAS, Á., 1996: Sobre la justificación de la autoridad, Madrid: Centro de Estudios Constitu-

${ }^{3}$ Cfr., RAZ, J., 1982: La autoridad del Derecho. Ensayos sobre derecho y moral (trad. de R. TAMAYO SALMORÁN), México: UNAM, pp. 23 y 45.
} 
mitiría explicar aquello en lo que la autoridad consiste, con total independencia de la tesis normativa que sobre su justificación se sostenga. Dicho de otra forma, se trataría de fijar un concepto (explicativamente neutro) de autoridad, válido para cualquier concepción (normativa) y obtenido, como mínimo común denominador, a partir de las diferentes concepciones disponibles sobre la autoridad. Pues bien, de acuerdo con RAZ, resulta del todo imposible construir un concepto explicativamente neutro de autoridad. Para esclarecer qué es una autoridad debemos primero saber qué es lo que nos lleva a afirmar que una determinada autoridad es legítima. Debemos, en suma, tener una teoría normativa respecto de qué es la autoridad legítima.

\subsection{Segundo: la autoridad como término de enlace. Las dos partes de la teoría de la autoridad}

RAZ distingue dos partes en su teoría de la autoridad. A saber: 1) las condiciones bajo las cuales se puede adquirir o sostener autoridad, y 2) qué es lo que se sigue cuando alguien tiene autoridad ${ }^{4}$. La distinción entre estas dos partes de la teoría me parece inobjetable, la cuestión que me parece más oscura es cómo se articulan estas dos partes entre sí. Ver la noción de autoridad como un término de enlace entre las dos partes de la teoría de la autoridad puede arrojar alguna luz a este respecto. Por ejemplo, recordemos que en el análisis rossiano del derecho de propiedad el concepto propiedad es concebido como un término de enlace que media entre una disyunción de hechos condicionantes y una conjunción de consecuencias normativas. De manera semejante, la noción de autoridad legítima puede concebirse como un término de enlace entre las dos partes de la teoría de la autoridad. El concepto de autoridad legítima serviría para enlazar ciertos hechos condicionantes con las consecuencias que se siguen de afirmar que alguien es una autoridad; operaría como un concepto bisagra que permite articular las condiciones bajo las cuales se puede adquirir o sostener autoridad, de un lado, con las consecuencias que se siguen de afirmar que alguien es autoridad, de otro.

Partiendo de esta propuesta de reconstrucción, no está de más que recordemos muy brevemente en qué consisten tales hechos condicionantes y cuáles son las consecuencias que llevan aparejadas. Empezando por las condiciones bajo las cuales se puede adquirir o sostener autoridad, RAZ señala que los requisitos serían dos: la tesis de la justificación normal y la condición de independencia [the independence condition] 5 . De acuerdo con la tesis de la justificación normal, «el destinatario se conformaría mejor con las razones que se le aplican (es decir, con las razones que no son las directivas de la autoridad) si intenta ser guiado por las directivas de la autoridad que si no lo hace». Por su parte, la condición de independencia supone «que las cuestiones respecto de las cuales se reúne la primera condición son tales que en relación a ellas es mejor conformarse con la razón que decidir por sí mismo, sin la ayuda de la autoridad». La idea de RAZ es que, para que la renuncia a decidir por nosotros esté justificada, debe estar en juego un bien sustancial y, además, tal renuncia no debe suponer

\footnotetext{
${ }^{4}$ Cfr. Raz, 2007: epígrafe 1, punto cuarto.

${ }^{5}$ Cfr. RAZ, 2007: epígrafe 2.
} 
«un menoscabo de la autenticidad de nuestra propia vida, o de nuestra habilidad de conducir una vida autosuficiente o satisfactoria» ${ }^{6}$.

En cuanto a las consecuencias que se siguen de afirmar que alguien tiene autoridad, éstas se concretarían en la llamada tesis del reemplazo. De acuerdo con dicha tesis, las directivas de la autoridad reemplazan a las razones subyacentes de aquellos que están sometidos a la autoridad ${ }^{7}$. Las autoridades no pueden cumplir con su función de mejorar nuestra conformidad con las razones subyacentes si sus directivas no nos llevan a actuar de manera diferente a como lo habríamos hecho de no existir tales directivas. La tesis del reemplazo muestra las implicaciones prácticas de la noción de autoridad. Si en el plano de los hechos condicionantes RAZ vincula las autoridades prácticas a las teóricas, ya que la justificación de aquéllas descansa en su carácter experto, en el plano de las consecuencias encontramos la diferencia: sólo las autoridades prácticas generan razones protegidas para la acción.

\subsection{Tercero: la extensión flexible del concepto de autoridad}

Aunque RAZ no emplea esta terminología, la extensión flexible del concepto de autoridad es una idea que ha estado presente en sus trabajos desde el principio. En este artículo vuelve a insistir nuevamente en que, debido a los elementos epistémicos que condicionan la autoridad, la concepción de la autoridad como servicio permite una considerable variabilidad en el alcance de la autoridad gubernamental sobre la población sobre la cual pretende autoridad ${ }^{8}$. Y en este sentido señala que «una persona $\mathrm{u}$ organismo ostenta autoridad con respecto a toda un área si esa persona u organismo reúne las condiciones relativas a esa área, y no hay ninguna parte apropiada del área con respecto a la cual se pueda reconocer que la persona u organismo falla en las condiciones» ${ }^{9}$. En suma, el ejercicio legítimo de las relaciones de autoridad está sujeto a condiciones epistémicas que son relativas a cada autoridad y a cada sujeto sometido a la misma, por lo que difícilmente comprenderá, para todos y cada uno de los individuos, todos y cada uno de los mandatos que las autoridades emiten. Repárese en que la incorporación de este elemento de flexibilidad convierte en vano todo esfuerzo por hacer ingresar la concepción de la autoridad como servicio en las filas de positivismo ideológico.

\subsection{Cuarto: la dimensión histórica del concepto de autoridad}

La dimensión histórica del concepto de autoridad no ha sido algo de lo que RAZ se haya ocupado de manera significativa. No obstante, en su último trabajo se incluye una reflexión a este respecto que resulta bien interesante ${ }^{10}$. RAZ contrapone un con-

\footnotetext{
${ }^{6}$ Cfr. RaZ, 2007: epígrafe 2.

Cfr. Raz, 2007: epígrafe 2.

Cfr. RAZ, 2007: epígrafe 3, apartado 7.

Cfr. RAZ, 2007: epígrafe 3, apartado 5.

10 Aunque — dicho sea de paso- también bastante menesterosa de desarrollo.
} 
cepto amplio de autoridad, «que comprendería la serie entera de conceptos ascendientes» ${ }^{11}$, a un concepto de autoridad "simpliciter", que sería «nuestro concepto de autoridad en tanto que sólo él es nuestra vía de acceso a todos sus ascendientes que se identifican por sus relaciones con él» ${ }^{12}$. Lo que RAZ parece querer indicarnos es que el concepto de autoridad puede ser abordado bien de forma compleja, incorporando aspectos relativos a su dimensión histórica, o bien desde una perspectiva sencilla y más actual, que se preocuparía centralmente de la forma en que hoy en día concebimos la autoridad. Es esta última aproximación la escogida por nuestro autor.

A lo largo de las páginas que siguen me iré apoyando en estos aspectos de la concepción raziana de la autoridad para ir construyendo mi crítica. El objeto de mi trabajo es doble: de un lado, cuestionar la tesis normativa contenida en la concepción de la autoridad como servicio. Y, de otro lado, cuestionar algunos de los presupuestos conceptuales sobre los que se asienta. Respecto de la tesis normativa, voy a tratar de mostrar que la concepción de la autoridad como servicio no es una concepción completa ${ }^{13}$, ya que no expresa ni el conjunto de condiciones necesarias para que se produzca justificadamente el reemplazo del juicio propio por el de otro sujeto, ni tampoco el conjunto de condiciones suficientes. La concepción expresaría el conjunto de condiciones necesarias para que se produjera el reemplazo si siempre debieran concurrir las condiciones especificadas en la misma para que tal reemplazo se produjera justificadamente; esto es, si únicamente cuando la autoridad fuera experta estuviera justificado el reemplazo. Pero voy a tratar de mostrar cómo, bajo ciertas condiciones, tiene sentido hablar de reemplazo aunque no haya pericia. En resumen, si hay autoridades que deben ser obedecidas, aunque con ello no maximicemos la conformidad con las razones subyacentes que nos son aplicables, la tesis de RAZ de que sólo puede tener autoridad legítima quien es autoridad teórica ${ }^{14}$ se desmorona.

Pero mi objeción va más allá. Como ya he apuntado, la concepción de la autoridad como servicio tampoco expresa el conjunto de condiciones suficientes para que se produzca el reemplazo. La concepción expresaría el conjunto de condiciones suficientes si siempre que concurrieran las condiciones especificadas en la concepción debiera producirse el reemplazo (aunque éste también pueda producirse bajo otras condiciones). Pero, a mi juicio, no basta con que se den las condiciones de la tesis de la justificación normal para que esté justificado el reemplazo. No siempre debemos obedecer a autoridades expertas, aunque éstas nos lleven a maximizar la conformidad con las razones que nos son aplicables. Trataré de especificar cuáles son las condiciones de otro tipo de situaciones en las que, pese a darse las condiciones contempladas en la concepción de la autoridad como servicio, resulta cuanto menos discutible que esté justificado el reemplazo, por lo que también respecto del requisito de la suficiencia la pretensión de completitud de la concepción falla nuevamente.

${ }^{11}$ RAZ es muy parco sobre toda esta cuestión. Se limita a señalar que un concepto es ascendiente «si el concepto que le sucedió surgió como una modificación del concepto ascendiente, y conservó respecto a él similitud suficiente, o bien en sus rasgos o bien en su función...», cfr. RAZ, 2007: epígrafe 1, punto quinto.

12 Cfr. Raz, 2007: epígrafe 1, punto quinto.

13 Sobre la pretensión de exhaustividad de la teoría, cfr. RAZ, 2007: epígrafe 1, punto cuarto.

${ }^{14}$ Cfr. RAZ, 2007: epígrafe 4. 
Debo aclarar que el fracaso en la pretensión de completitud no es algo que por sí mismo me parezca criticable, pues, a mi juicio, la pretensión de completitud es sencillamente imposible de satisfacer. Las razones de mi crítica a RAZ son de otra índole, y se concretarían en tres objeciones metodológicas interrelacionadas que poco a poco irán aflorando a lo largo de estas páginas: en primer lugar, RAZ ignora las razones por las cuales la pretensión de completitud resulta imposible de satisfacer. En segundo lugar, su concepción no es integradora; a lo largo de su trabajo aparece concebida -más allá de lo que sería un mero recurso estilístico- como una concepción competitiva frente a otras rivales. Y, finalmente, por decirlo con su propia terminología, RAZ renuncia a elaborar un concepto amplio de autoridad, en beneficio de un concepto "simpliciter".

La estrategia que voy a desplegar va a ser la siguiente: en primer lugar, en el próximo apartado dibujaré a grandes rasgos las características genéricas de dos tipos de situaciones comprometedoras para la concepción de la autoridad como servicio. En la primera de dichas situaciones, pese a no darse las condiciones establecidas en la tesis de la justificación normal, tiene pleno sentido postular el reemplazo del juicio propio del sujeto por las directivas procedentes de la autoridad. Mientras que, en la segunda, dándose las condiciones, no tiene sentido el reemplazo. Por supuesto, ambas situaciones no son sino ejemplificaciones que tomo como punto de partida para mostrar, en el siguiente apartado, algunos argumentos clásicos empleados a lo largo de la historia de la filosofía política para justificar la autoridad política. Recalar en ellos y no hacer borrón y cuenta nueva me permitirá, en el último apartado, extraer alguna lección útil de cara a la articulación de una concepción integradora de la autoridad.

\section{ALGUNAS SITUACIONES COMPROMETEDORAS}

Quiero someter a la consideración del lector dos tipos de situaciones, a las que me voy a referir, respectivamente, como 1) el caso de las autoridades emergentes no expertas y 2) el caso de las autoridades democráticas no expertas. Voy a tratar de mostrar que, en ambos casos, pese a no darse las condiciones establecidas en la tesis de la justificación normal, puede tener pleno sentido postular el reemplazo del juicio del propio sujeto por las directivas procedentes de la autoridad.

\subsection{El caso de las autoridades emergentes no expertas: las autoridades hobbesianas}

Imaginemos una situación de vacío de poder en la cual sólo un individuo -o grupo de individuos que actúan colegiadamente- es capaz de imponer su voluntad sobre el conjunto de la población de forma tal que, aunque no se garantizan en su integridad los derechos fundamentales de los individuos, quedan asegurados ciertos bienes mínimos que son necesarios para la supervivencia de los individuos y que de otra forma no lo estarían. Se trata de bienes vinculados a derechos tan elementales como son el derecho a la vida o a la integridad física. Es fundamental para que mi ejemplo funcione que no puedan procurarse tales bienes primarios de ninguna 
otra forma; no debe haber una alternativa viable a la de la autoridad de facto emergente.

Como mi lector habrá podido adivinar, estoy pensando en un tipo de relación de autoridad próxima al modelo hobbesiano. Presupone una situación de vacío de poder en la que el hombre bien puede ser visto como un lobo para el hombre. Si en un contexto tal la autoridad de un individuo consiguiera imponerse sobre los demás, bien podría predicarse de la misma un cierto tipo de legitimidad. Se trataría, eso sí, de una legitimidad basada en argumentos de tipo mal menor: la autoridad es un mal que hay que tolerar, ya que la alternativa de su desaparición implicaría un riesgo mayor para la vida e integridad de los sujetos. En suma, tener autoridades resulta preferible a la alternativa de no tenerlas. La autoridad es institucionalmente necesaria para la supervivencia de los individuos que integran el colectivo.

No pretendo que las autoridades de facto emergentes ostenten un derecho a mandar - correlativo a un deber de obediencia - ilimitado. Tal derecho no estaría siempre fundamentado: no lo estaría, por ejemplo, si la materia sobre la que legislaran menoscabara gravemente los derechos fundamentales tanto de los individuos a ella sometidos como de cualquiera otros. Tampoco lo estaría en aquellos casos en los que la disidencia pudiera provocar una mejora en el comportamiento de la autoridad emergente, o si no tuviera coste alguno de cara a su estabilización (por ejemplo, si no es previsible que nadie se percate del acto de desobediencia). La repercusión pública de la desobediencia nos lleva, por último, a la clase de destinatarios de las directivas autoritativas: no se miden igual las consecuencias de la desobediencia de jueces y órganos de aplicación y ejecución del Derecho, que la del resto de ciudadanos. Es la conducta de aquéllos y no de estos últimos la que suele ser decisiva para la supervivencia del Derecho y, con ella, de la autoridad política.

Pero todavía es necesario enriquecer algo más los rasgos de este primer tipo de situación comprometedora para la concepción de la autoridad como servicio. A continuación voy a exponer cuatro posibles objeciones a la legitimidad de las autoridades hobbesianas y a tratar de rebatirlas. Los argumentos que emplee para rebatir estas objeciones me ayudarán a terminar de esbozar las características de la relación hobbesiana de autoridad en la que estoy pensando.

\subsubsection{Un modelo de autoridad muy atrás en el tiempo}

Una primera objeción que se podría dirigir a mi ejemplo es que el tipo de relación de autoridad del que se ocupa queda muy atrás en el tiempo; el tipo de argumentos que emplea podían estar bien para el contexto histórico-político en que HOBBES escribía, pero no son argumentos idóneos para la era moderna. En el contexto actual, una situación como la aquí descrita puede parecer algo forzada, casi de laboratorio. No obstante, a poco que reflexionemos, podemos encontrar instancias de aplicación de la misma, sin necesidad de retrotraernos mucho en el pasado: ésta podía ser la situación en el Líbano en los ochenta. Y, si se prefiere un ejemplo todavía más reciente, la situación no difiere mucho de lo que una prognosis realista puede augurar para Irak en un futuro inmediato. Si en situaciones como éstas un individuo o grupo de individuos estuviera en condiciones de imponer su voluntad por encima de la de los demás, 
de manera que se pudiera poner término al tremendo coste de vidas humanas que conlleva la situación de vacío de poder, probablemente podríamos predicar de ella cierto tipo de legitimidad.

\subsubsection{Una autoridad "a la carta"}

Otra objeción que se podría dirigir a mi ejemplo es que éste es tramposo, ya que no fundamenta una legitimidad tan amplia como la que la autoridad emergente pretende. La autoridad emergente pretende autoridad respecto de todos sus mandatos, en todos los casos y respecto de todos los ciudadanos, pero en mi ejemplo sólo lo consigue respecto de ciertas materias - las que no comprometen seriamente Derechos fundamentales - , en ciertos casos - los especialmente sensibles a la desobedienciay respecto de ciertos sujetos — básicamente jueces y órganos de aplicación y ejecución del Derecho-. Se trataría, en suma, de algo así como una autoridad a la carta. Ahora bien, por extraño que parezca, para contraatacar esta objeción tengo en RAZ a mi mejor aliado. Como destaqué en la introducción, debido a los elementos epistémicos que condicionan la autoridad, RAZ mantiene una extensión flexible del concepto de autoridad: la concepción de la autoridad como servicio permite una considerable variabilidad en el alcance de la autoridad gubernamental sobre la población respecto de la que se pretende autoridad. Por lo tanto, la admisibilidad o no de una autoridad como la hobbesiana dependerá de si somos capaces de fijar de manera más o menos estable ciertas áreas, variables según los destinatarios, en las cuales el reconocimiento de un derecho a mandar de la autoridad sea legítimo. Si tal cosa es lógicamente posible respecto de las autoridades expertas de RAZ, me parece difícil negar que lo pueda ser respecto de las autoridades hobbesianas.

Quizás sea conveniente aclarar aquí que el reconocimiento del derecho a mandar de una autoridad - y del correlativo deber de obedecerla- dentro de cierta área es algo que puede ser cuestionado bajo ciertas circunstancias. No puede serlo lógicamente en todos los casos en los que se produce la ocasión de cumplir con los mandatos la autoridad, pues en tal caso dejaríamos de tener autoridades prácticas, pero sí puede serlo eventualmente. No me es posible ocuparme aquí de las circunstancias en las que tal cuestionamiento es aceptable, pero me parece importante destacar que sólo podría serlo cuando llevara consigo una revisión del área en relación con la cual reconocemos autoridad ${ }^{15}$. Ya sea ésta una autoridad de tipo hobbesiana o raziana.

\subsubsection{Deber de obediencia sin autoridad}

También se podría objetar a mi ejemplo que, en las situaciones como las arriba descritas, sólo se podría hablar de una obligación política, que se concretaría en un deber restringido de obediencia, pero no de un genuino reconocimiento de autoridad. Lo único que el ejemplo de las autoridades hobbesianas lograría mostrar es la existencia de un deber fundado de obedecer al Derecho (dentro de los límites antes per-

${ }^{15}$ Cfr. Ródenas, A., 1996: pp. 171 y ss. 
filados), pero nunca la legitimidad de la fuente emisora de los mandatos. Esta objeción tendría todo el sentido si no fuera posible delimitar áreas en las que pudiéramos hablar de un deber de obediencia justificado, pero, como acabamos de ver, si tal cosa es posible respecto de las autoridades expertas, debe serlo también respecto de las hobbesianas.

Si tiene sentido hablar de un deber restringido de obediencia en estos contextos, ¿por qué no hablar entonces de un correlativo derecho a mandar de la autoridad? O, dicho en otros términos, ¿de una relación legítima - aunque restringida a ciertas áreas- de autoridad? La única objeción seria que se podía hacer a este argumento pasaría por demostrar que estamos en presencia de un deber de obediencia que no sería el correlato de un derecho a mandar: aunque efectivamente podríamos hablar de un deber de obediencia a la autoridad emergente, sería dudoso que otro tanto cupiera respecto del derecho a mandar de ésta. Pero entonces la pregunta es: ¿por qué cuando una autoridad se fundamenta en la pericia - maximización de la correspondencia con las razones subyacentes que tiene el agente- sí hablamos de un derecho a mandar, pero cuando se fundamenta hobbesianamente tal cosa no es posible? A mi juicio, la plausibilidad de una justificación de la autoridad como la hobbesiana depende de si, para tales casos, podemos hablar, en algún sentido intersubjetivamente aceptable, de un derecho a mandar correlativo a un deber de obediencia. Pienso que tal cosa es posible. Pero mostrar cómo lo es y, sobre todo, de qué forma resulta conciliable con otras formas de fundamentar las autoridades políticas es algo que tendrá que ser postergado por unas páginas.

\subsubsection{El ejercicio de autoridad en contextos ordinarios}

Finalmente, se le podría objetar a mi ejemplo que, aunque eventualmente pueden producirse situaciones como las en él descritas, se trata de situaciones extraordinarias, que no dan cuenta de lo que es el ejercicio ordinario de autoridad. Los contextos ordinarios de ejercicio de autoridad son contextos competitivos, en los que más de un sujeto - o conjunto de sujetos- compiten entre sí por ocupar la posición de autoridad política, sin que el coste de una transacción suponga la pérdida de bienes esenciales para la supervivencia de los individuos. En situaciones ordinarias no seguir los mandatos de una autoridad (de facto) no nos lleva sin más a un vacío de poder. Si una autoridad de facto no es capaz de maximizar la conformidad con las razones subyacentes que tienen los individuos, ésta puede ser reemplazada por otra sin pagar por ello un coste excesivamente dramático. Ésta es sin duda una de las ventajas que acostumbramos a asociar a ejercicio democrático del poder político.

Esta objeción relativizaría el alcance del argumento hobbesiano: aunque pueda haber supuestos residuales, en los que cabe hablar de una autoridad legítima pero no experta, estos supuestos sólo lograrían mostrar que la pericia no siempre es condición necesaria para el ejercicio legítimo de autoridad, pero en modo alguno que no sea condición suficiente: siempre que concurran las condiciones especificadas en la concepción de la autoridad como servicio debe producirse el reemplazo.

Contestaré a la objeción en la próxima sección, pero anticipo que no me parece contundente. Creo que en contextos ordinarios de ejercicio de poder también pueden 
producirse otro tipo de situaciones que resultan comprometedoras para la concepción de la autoridad como servicio y que, por lo tanto, la pericia tampoco es siempre condición suficiente para el ejercicio legítimo de la autoridad. Veamos en qué pueden consistir tales situaciones.

\subsection{El caso de las autoridades democráticas no expertas: la autoridad de Juan Triquiñuelas y la de Perfecto Morales}

Supongamos pues que el contexto de ejercicio de la relación de poder ha cambiado. Ahora contamos con una situación mucho más estable, en la que una autoridad puede sustituir a otra sin tener que afrontar los dramáticos costes del vacío de poder. La pregunta pertinente es ¿siempre hay que obedecer en este contexto a las autoridades expertas? Si obedeciendo la reputada autoridad práctica de Perfecto Morales me ajusto mejor a las razones subyacentes que me son aplicables que obedeciendo a Juan Triquiñuelas, y el coste de la desobediencia no es - por definición- la vuelta a una situación de vacío de poder, ¿tiene sentido afirmar que en ocasiones debo obedecer a Juan Triquiñuelas? No nos precipitemos en responder. El candidato más idóneo a autoridad legítima parece ser Perfecto Morales, pero ¿qué sucede si Juan Triquiñuelas es una autoridad democrática y Perfecto Morales no lo es?

RAZ no se deja impresionar por la contundencia de mi ejemplo. Nunca el argumento democrático ha jugado papel alguno en su concepción de la autoridad y en este último trabajo explícitamente desprecia la virtualidad del mismo ${ }^{16}$. Pero ¿se puede pasar por alto - y de un plumazo — varios siglos de filosofía política?

No puedo ocuparme aquí de la gran cantidad de argumentos y concepciones desde los que se ha defendido la autoridad democrática. Pero, pasando muy de puntillas por la cuestión, las concepciones democráticas de la autoridad más significativas podrían ordenarse de acuerdo con una escala que iría de un menor a mayor grado de confianza en el procedimiento democrático. Así, en el nivel menos comprometido se hallarían, por ejemplo, las teorías elitistas, que sitúan la ventaja del procedimiento democrático de toma de decisiones en la facilidad para la sustitución de las elites en el poder. Las concepciones participacionistas, por su parte, mantendrían un grado de confianza mayor que el elitismo, al postular que la democracia genera procedimientos para que los individuos introduzcan sus intereses en el juego político. El compromiso más alto con el procedimiento democrático lo asumirían las concepciones discursivistas o deliberativas de la democracia, para las que la democracia constituiría una forma privilegiada de acceso a la verdad moral.

En suma, las diferentes concepciones de la democracia atribuyen un valor diferente al proceso democrático. No es necesario suscribir ninguna de ellas en su integridad para reconocer a cada una un punto de razón: la democracia facilita, en primer lugar, el reemplazo de una autoridad por otra sin pagar por ello en coste dramático; posibilita, en segundo lugar, la participación de los ciudadanos en la toma de decisiones públicas; puede favorecer, en tercer lugar, el acceso a decisiones moralmente

${ }^{16}$ Cfr. RAZ, 2007: epígrafe 3, apartado 8 y especialmente la nota a pie de página n. ${ }^{\circ} 20$. 
correctas. La suma de esta versión débil (o, si se quiere, descafeinada) de los argumentos esgrimidos desde las anteriores concepciones en la defensa del procedimiento democrático arroja un resultado ciertamente modesto, pero - como se verá- extraordinariamente productivo: la democracia es una práctica valiosa, cuya continuidad constituye un bien colectivo que debe ser preservado.

Por supuesto, no pretendo sostener aquí que para preservar la práctica democrática haya que obedecer siempre a las autoridades democráticas. Ni siquiera desde aquellas de las concepciones anteriores que están más comprometidas con la democracia se ha sostenido una tesis de un calibre tan grueso. El argumento del valor de la práctica está sometido a restricciones análogas a las que hemos visto que condicionaban el valor de las autoridades hobbesianas. Para empezar, resulta bastante discutible que el argumento sea de aplicación en aquellos casos en los que la materia regulada por la autoridad democrática menoscabe gravemente derechos fundamentales de individuos (estén sometidos éstos a la autoridad o no). Además, sólo nos vincula en aquellos casos en los que haya razones para temer que la desobediencia pueda suponer un menoscabo de la práctica. Pero esto no es algo que acontezca en relación a todos los mandatos que emiten las autoridades democráticas. La fuerza de tales razones variará en función de circunstancias tales como la naturaleza de la materia regulada o cuál sea el sujeto destinatario de la misma. A nadie se le escapa que, de cara a la pervivencia de una práctica, no acostumbra a ser el mismo el coste de la desobediencia de un sujeto particular a una norma, que la desobediencia de un órgano encargado de velar por el cumplimiento del Derecho.

Pero si, al examinar el caso de las autoridades hobbesianas, ya habíamos asumido que la pericia no es condición necesaria del ejercicio legítimo de autoridad, ¿a qué viene ahora el argumento del valor de la práctica?: tanto en el caso de las autoridades hobbesianas, como en el de las democráticas, consideraciones distintas a las de la experiencia de la autoridad nos pueden llevar al reconocimiento de ciertas autoridades de facto como legítimas respecto de determinadas áreas. Para mostrar qué es lo que aporta de nuevo el argumento del valor de la práctica debemos volver otra vez a las condiciones de partida. Como se recordará, nos encontrábamos en una situación en la que la autoridad práctica de Perfecto Morales entra en conflicto con la democrática - aunque no experta- de Juan Triquiñuelas. Obedecer a Perfecto Morales maximiza la correspondencia con las razones subyacentes que nos son aplicables, pero hacerlo siempre (aun dentro del área de autoridad que está justificado atribuirle) puede poner en entredicho la continuidad de una práctica que estimamos valiosa en su conjunto.

Pues bien, si en determinados casos hay razones para dejar de lado lo que dice la autoridad experta de Perfecto Morales y seguir los dictados de la autoridad no experta de Juan Triquiñuelas, ¿no diríamos que tales razones tienen que ver con la legitimidad que le atribuimos a una determinada forma de gobierno? Y ¿por qué estas consideraciones basadas en la forma de gobierno no son razones idóneas en las que fundar la legitimidad de una autoridad?

RAZ podría acusarme - en el improbable caso de que leyera estas páginas- de haber vuelto a mezclarlo todo: con su concepción de la autoridad como servicio él ha tratado de contestar a la pregunta de cuándo es racional el reemplazo del propio juicio 
de un sujeto por el de la autoridad, dejando a un lado la cuestión de la obligación política para con las autoridades democráticas. Pero precisamente lo que pretendo mostrar con mis dos ejemplos es que esta escisión no puede llevarse a cabo de una manera tan tajante; que, aunque la concepción de la autoridad como servicio puede ser operativa en una gran cantidad de ocasiones, su fuerza no es incondicionada y puede quedar relegada por otras consideraciones que también están conexas a nuestra comprensión de lo que es una autoridad legítima. Tanto en el caso de las autoridades hobbesianas, como en el de las democráticas no expertas, obtenemos argumentos pertinentes para fundar (en relación con determinadas áreas) un derecho a mandar de la autoridad correlativo a un deber de obediencia. En suma, argumentos capaces de justificar el reemplazo del propio juicio de un sujeto por el de la autoridad. Aunque ciertamente tales argumentos no tendrían un carácter absoluto y su aplicabilidad dependería de las circunstancias del contexto, si es posible hablar de áreas de ejercicio legítimo de la autoridad en el caso de las autoridades expertas, nada excluye que lo pueda ser también en el caso de las hobbesianas y en el de las democráticas no expertas.

\section{DOS ARGUMENTOS PERTINENTES}

Recordemos que lo que nos ha llevado hasta aquí ha sido la demanda de respuesta a la siguiente pregunta: ¿Qué es lo que funda el derecho a mandar de quien pretende autoridad? $\mathrm{O}$, dicho de manera más precisa, ¿qué argumentos pueden justificar el reemplazo del juicio propio por el de la autoridad? Sabemos que la respuesta de RAZ se funda en el mayor grado de pericia de la autoridad. De acuerdo con la concepción de la autoridad como servicio sólo el carácter de experto de la autoridad sería un candidato idóneo para responder a estas preguntas. La concepción de RAZ resulta persuasiva porque prescinde de los aspectos históricos y sociopolíticos que operan en el trasfondo de toda relación de autoridad. Como en un ensayo de laboratorio, al individuo se le aísla de toda contaminación contextual y se le sitúa frente a frente con la autoridad. En este ambiente aséptico el sujeto mantiene que sólo debe obedezcer cuando, al así hacerlo, maximiza la correspondencia con las razones que le son aplicables. Pero, a mi juicio, la concepción resulta también empobrecedora, pues, al prescindir del contexto histórico y sociopolítico que acompaña a toda relación de autoridad, hace borrón y cuenta nueva de algunos argumentos que nos son familiares y que han sido empleados recurrentemente por la filosofía política. Dos de estos argumentos, los que he llamado el argumento hobbesiano y el democrático, han sido esbozados en las páginas anteriores. Es hora de volver nuevamente sobre los mismos para terminar de explicar cómo de cada uno de ellos se deduce una razón que fundamenta un derecho a mandar de la autoridad correlativo a un deber de obediencia de los a ella sometidos.

\subsection{El argumento hobbesiano}

El argumento hobbesiano se reduce a mostrar las ventajas de contar con autoridades políticas, frente a la alternativa de no tenerlas. Viene a decir que las cosas están mejor si tenemos autoridades que sin ellas. Fundamenta, en suma, la necesidad insti- 
tucional de la relación de autoridad. Pero ¿cuándo resulta operativo el argumento hobbesiano?, ¿cuándo es preferible tener una autoridad al estado de naturaleza? La repuesta debe organizarse en diferentes niveles. En el nivel más elemental, que es del que yo me he ocupado en mi ejemplo, la autoridad resultaría justificada cuando, de no tenerla, se pusiera en peligro bienes básicos como la vida o la integridad de las personas. La autoridad, sencillamente, garantizaría la supervivencia y la integridad física de los individuos a ella sometidos.

Pero, presupuesto el nivel inferior, cabría todavía una respuesta más elaborada, dispuesta en una grada superior. De acuerdo con la misma, la autoridad estaría justificada cuando garantizara una estabilidad mínima tal que hiciera posible el desarrollo de (al menos) algunos planes de vida. Aquí los bienes asegurados no serían ya sólo la vida y la integridad física de los individuos, sino valores como la seguridad jurídica o la eficiencia en la consecución de acciones coordinadas entre sujetos ${ }^{17}$. Aunque no sea éste el lugar para mayores abundamientos, indiscutiblemente ambos aspectos son presupuestos indispensables para el desarrollo de los planes de vida de los individuos. Difícilmente los sujetos podríamos desarrollar un plan de vida autónomo si viviéramos rodeados de incertidumbre respecto de cuáles pueden ser las consecuencias de nuestra conducta. Y otro tanto sucedería si, por la ausencia de una acción coordinada entre individuos, no se pudiera atender a necesidades esenciales para el desarrollo de nuestros planes de vida.

Sea cual sea el nivel argumentativo en el que nos situemos, la pregunta pertinente parece ser ésta: ¿cuando justificamos la autoridad como un mal menor, nuestra argumentación es también moral? De no ser así, RAZ tendría toda la razón al ignorar un argumento como éste. Pero me parece que el argumento debe figurar entre los candidatos a justificar (moralmente) las relaciones de autoridad. Cuando utilizamos el argumento hobbesiano estamos afirmando que es moralmente preferible una autoridad de facto no experta, que una situación de vacío de poder en la que no se garantizan bienes elementales para la supervivencia humana, ni se dan las condiciones para el desarrollo de los planes de vida de los sujetos. De la preferibilidad moral de una situación frente a la otra puede derivarse - como ya hemos visto- un deber de obediencia en ciertos casos y respecto de ciertos sujetos. Puede derivarse, en suma, una obligación de reemplazo del juicio propio del sujeto por el de la autoridad en ciertas áreas.

Sea como fuere, es más probable que la resistencia de RAZ a la consideración de este tipo de argumentos se base en un presupuesto metodológico fundamental para su concepción: como se recordará, una de las piedras angulares sobre las que descansa

${ }_{17}$ Cuando RAz se ocupa de descartar como rival de la concepción de la autoridad como servicio el argumento de la coordinación, en realidad está descartando una de las razones que estoy dando aquí como fundamento del argumento hobbesiano. La estrategia de RAZ es la siguiente: reconducir el argumento de la coordinación al de la autoridad experta. En la concepción de la autoridad como servicio la autoridad es también experta en materia de coordinación; sabe detectar cuándo hay un problema de coordinación mejor que los individuos a ella sometida y, además, es capaz de implementar la mejor solución a los problemas de coordinación. Esta estrategia raziana plantea dificultades de las que no me es posible ocuparme aquí (cfr. BAYÓN, J. C., 1991: La normatividad del Derecho, deber jurídico y razones para la acción, Madrid: Centro de Estudios Constitucionales, pp. 666 y ss., y RóDENAS, A., 1996: pp. 187 y ss.), ahora sólo me interesa destacar que el argumento hobbesiano puede fundarse en razones diferentes a las de la coordinación. 
la concepción de la autoridad como servicio es la dependencia del concepto de autoridad de facto respecto del de autoridad legítima. Para RAZ el concepto de autoridad legítima es previo al de autoridad de facto. Ahora bien, aceptar el argumento hobbesiano supondría asumir que la legitimidad de ciertas autoridades depende de que sean autoridades de facto. Sólo aquellas autoridades que lo son de facto podrían ser autoridades legítimas en sentido hobbesiano. La única autoridad que interesa al argumento es la que consigue imponerse en una situación de vacío de poder. De ahí que la noción de autoridad legítima parezca depender de que se sea autoridad de facto y no a la inversa, como RAZ pretende ${ }^{18}$.

\subsection{El argumento democrático}

El argumento democrático, como se recordará, fundamenta la exclusividad de ciertas formas de autoridad en contextos competitivos, en los que dos o más sujetos compiten entre sí por ocupar la posición de autoridad política, sin que el coste de la sustitución de un sujeto por otro ponga en peligro bienes esenciales para la supervivencia de los individuos. Lo que el argumento muestra es que la autoridad democrática es mejor forma de gobierno que otras rivales. Este argumento nos ha resultado especialmente productivo, ya que puede llegar a fundamentar un deber de obediencia a la autoridad democrática incluso cuando ésta no es experta y compite con otra autoridad que sí lo es. El argumento muestra, en suma, que la pericia no es condición necesaria para el reemplazo.

La pregunta que nos hacemos aquí ya no es ¿por qué es mejor tener una autoridad que no tener ninguna?, sino ¿qué tienen de valioso ciertos tipos de autoridades? $\mathrm{o}$, si se prefiere, ¿qué hay de valioso en ciertas formas de ejercicio de poder? Aun cuando no seamos unos entusiastas del procedimiento democrático y sólo concedamos que la democracia constituye una práctica que reviste algún valor, la respuesta que hemos dado a la pregunta tiene también carácter moral. Este tipo de razones son susceptibles de prefigurar un área en la que queda también justificado el reemplazo del juicio propio por el de la autoridad democrática.

Hasta aquí mi esfuerzo ha consistido en tratar de mostrar cómo ni el argumento hobbesiano ni el democrático constituyen meros sedimentos que se hallan depositados en los estratos más profundos de nuestra concepción de la autoridad. Antes al contrario, nos proporcionan razones que se hallan sobreentendidas, aunque no siempre seamos conscientes de que operamos con ellas, pero, sobre todo, que tienen la capacidad de resurgir cuando el contexto lo torna oportuno y pueden, eventualmente, medirse con los argumentos que proporciona la concepción de la autoridad como servicio. Son, en suma, razones plenamente operativas.

\footnotetext{
18 Ahora bien, es posible que el argumento hobbesiano no precise tanto como lo que parece, de manera que pueda ser asumido sin traicionar los presupuestos metodológicos razianos. El argumento puede funcionar también respecto de todo agente capaz de ejercer el del monopolio de la fuerza física, sin que tenga por qué acompañarle una pretensión de legitimidad y, por lo tanto, sin que sea necesario predicar de él una autoridad de facto. En todo caso, cuanto menos de cara a la estabilización de las relaciones de poder, la incorporación de la pretensión de legitimidad se plantea como un requisito irrenunciable.
} 


\section{COMPLETANDO EL PUZZLE: UNA CONCEPCIÓN INTEGRADORA DE LA AUTORIDAD}

Si mi análisis precedente no es errado, la opción de considerar el argumento hobbesiano y el democrático como muestras de conceptos ascendientes de autoridad, superados por nuestro concepto actual, está destinada al fracaso. La pregunta oportuna ahora parece ser cómo encajar todos estos argumentos en una concepción integradora de la autoridad. Trataré de explicar cómo se organizan todos estos elementos recurriendo a una imagen procedente de una disciplina totalmente diferente: se trata de la imagen de la estructura del cerebro humano generada por las neurociencias. De acuerdo con los neurocientíficos, el cerebro sería una cierta clase de sitio arqueológico, con la capa más externa compuesta de la estructura cerebral más reciente. Las capas más hondas del cerebro contienen estructuras de nuestros primeros antepasados evolutivos, que son los reptiles y los mamíferos. Es así que el cerebro humano ha evolucionado de tal manera que ha formado tres capas cerebrales producto de diferentes etapas evolutivas, pero conservando las funciones de cada capa cerebral.

De manera semejante, nuestra concepción actual de la de autoridad es el resultado de una sucesión histórica de necesidades, experiencias y reflexiones que va generando una serie de construcciones teóricas que se superponen, sin que por ello lleguen necesariamente a anularse o excluirse. Muchas de estas construcciones conservan su funcionalidad y proporcionan genuinas razones operativas, aunque en algunos contextos argumentativos operen entimemáticamente: si damos por justificado el reemplazo del juicio propio por el de una autoridad experta es porque, para empezar, presuponemos una relación de autoridad en un contexto ordinario, en el que no hay bienes elementales para la supervivencia en juego. Y porque presuponemos también, en segundo término, que no está en peligro la continuidad de una práctica que, como la democrática, nos parece valiosa. Cuando ambos presupuestos son cuestionados es cuando se tornan operativos los argumentos en los que se sustentan y son capaces de generar razones para el reemplazo del juicio propio por el de la autoridad. Es en tal caso cuando la concepción de la autoridad como servicio resulta — de acuerdo con lo que hemos visto- insatisfactoria.

Precisando algo más la imagen de una concepción integradora de la autoridad tendríamos que, en primer término, en los estratos más profundos de dicha concepción, estaría ubicada una fundamentación de la autoridad de tipo hobbesiano, basada en las ventajas de contar con autoridadades que permitan resolver conflictos entre individuos. Un segundo estrato lo ocuparía una fundamentación de la autoridad basada en las ventajas de la forma de gobierno - como sucede con las autoridades democráticas-. Aquí los argumentos se tornan algo más sofisticados, pues se presume una situación competitiva, en la que dos o más sujetos pugnan entre sí por ocupar la posición de autoridad política, sin poner en peligro bienes esenciales para la supervivencia. La pregunta a la que se trata de contestar ahora ya no es ¿por qué es mejor tener una autoridad que no tener ninguna?, sino, como ya he indicado anteriormente, ¿qué tienen de valioso ciertos tipos de autoridades? o, si se prefiere, ¿qué hay de valioso en ciertas formas de ejercicio de poder? Finalmente, el estrato más reciente lo ocuparían aquellos argumentos que ponen su énfasis en el valor de lo ordenado por la 
autoridad. Aquí lo que cuenta es el propio contenido de lo ordenado y, más concretamente, la maximización de la correspondencia de lo ordenado con aquello que, de acuerdo con las razones subyacentes que le son aplicables al sujeto, a éste le es obligado hacer.

En suma, nuestra compresión de lo que es una autoridad legítima no descansa sólo - como RAZ pretende - en su capacidad para maximizar la conformidad a las razones subyacentes que nos son aplicables. En ciertos contextos también entendemos por autoridades legítimas aquellas que sencillamente resultan institucionalmente necesarias para la supervivencia de los individuos o a aquellas otras que, sin llegar a estos extremos, permiten la continuidad de prácticas sociales valiosas como la democrática.

Como no podría ser de otra forma, estos tres estratos tienen su trasunto en la pretensión de legitimidad que caracteriza a quien recaba para sí autoridad política. Si nos detenemos por un instante en esta cuestión, veremos que también aquí es posible desglosar en tres componentes dicha pretensión: en un nivel más elemental, quien pretende autoridad mantiene que su existencia está institucionalmente justificada, en el sentido de que para los a ella sometidos es más ventajoso tener una autoridad que les gobierne que una situación de vacío de poder. Los argumentos hobbesianos que aquí hemos explorado tratan precisamente de satisfacer esta demanda. Pero, además, quien pretende autoridad también mantiene que ostenta un derecho exclusivo a mandar, ya que existen razones para que sólo ella emita mandatos, dentro del ámbito de competencia que reclama para sí, sin que esta función le pueda ser disputada por ninguna otra autoridad potencial. Los argumentos basados en las ventajas de la forma democrática de gobierno serían los candidatos idóneos a colmar esta pretensión. Y, finalmente, la pretensión de autoridad iría indisociablemente unida a una pretensión de corrección o, lo que es lo mismo, de que aquello que la autoridad ordena como debido maximiza la conformidad con las razones subyacentes que el agente tiene. Es aquí donde tendrían su encaje argumentos como los de la autoridad experta barajados por RAZ en la concepción de la autoridad como servicio. En suma, disociar el análisis de la pretensión de autoridad en estos tres componentes nos permitiría estrechar el círculo en torno a lo que debe ser una concepción integradora de la autori$\operatorname{dad}^{19}$.

Para ir concluyendo, lo aquí expuesto trata de mostrar las ventajas de mantener lo que he llamado una concepción integradora de la autoridad. Una concepción integradora que se caracterizaría por dos rasgos: su complejidad y su carácter abierto. Se trata de una concepción compleja, pues asume que el carácter histórico y contextual del concepto de autoridad es un dato que en modo alguno puede ser obviado. De modo que más de un argumento racional es candidato a incorporarse a la concepción, sin que la organización por estratos de tales argumentos suponga la superación de los más antiguos por los recientes. Antes al contrario - como vimos que sucedía con los estratos del cerebro humano-, cada estrato anterior conserva su funcionalidad. Es por ello que la concepción integradora de la autoridad no mantiene una pretensión de superioridad frente a otras concepciones rivales, sino que, por el contrario, trata 
de componer con todas aquellas que nos resultan inteligibles un mosaico ordenado y coherente. Lo cual nos lleva, por último, al otro rasgo que he predicado de la concepción integradora de la autoridad: su carácter abierto. Se trata de una concepción abierta, puesto que renuncia, por vana, a toda pretensión de completitud. La concepción no puede nunca terminar de expresar el conjunto de condiciones necesarias y suficientes para el reemplazo, pues, a medida que surgen nuevas necesidades y experiencias, se van estratificando nuevos argumentos que se van incorporando a la concepción, enriqueciéndola constantemente. 